This item was submitted to Loughborough's Research Repository by the author.

Items in Figshare are protected by copyright, with all rights reserved, unless otherwise indicated.

\title{
Photo inactivation of virus particles in microfluidic capillary systems
}

PLEASE CITE THE PUBLISHED VERSION

http://dx.doi.org/10.1002/bit.25912

\section{PUBLISHER}

(c) John Wiley \& Sons, Inc.

\section{VERSION}

AM (Accepted Manuscript)

\section{PUBLISHER STATEMENT}

This work is made available according to the conditions of the Creative Commons Attribution-NonCommercialNoDerivatives 4.0 International (CC BY-NC-ND 4.0) licence. Full details of this licence are available at: https://creativecommons.org/licenses/by-nc-nd/4.0/

\section{LICENCE}

CC BY-NC-ND 4.0

\section{REPOSITORY RECORD}

Ren, Yudan, Colin M. Crump, Malcolm R. Mackley, Gianluca Li Puma, and Nuno M. Reis. 2016. "Photo Inactivation of Virus Particles in Microfluidic Capillary Systems". figshare. https://hdl.handle.net/2134/19998. 


\section{Photo inactivation of virus particles in microfluidic capillary systems}

Yudan Ren ${ }^{1}$, Colin M Crump ${ }^{1}$, Malcolm M Mackley ${ }^{2}$, Gianluca Li Puma, ${ }^{3}$ Nuno M Reis $^{2,3, *}$

${ }^{1}$ Division of Virology, Department of Pathology, University of Cambridge, Tennis Court Road, Cambridge CB2 1QP, United Kingdom

${ }^{2}$ Department of Chemical Engineering and Biotechnology, University of Cambridge, New Museums Site, Pembroke Street, Cambridge CB2 3RA, United Kingdom

${ }^{3}$ Department of Chemical Engineering, Loughborough University, Loughborough LE11 3TU, United Kingdom; telephone: +44(0) 1509222 505; e-mail: n.m.reis@lboro.ac.uk

*Correspondence to: N. M. Reis 


\begin{abstract}
It has long been established that UVC light is a very effective method for inactivating pathogens in a fluid, yet the application of UVC irradiation to modern biotechnological processes is limited by the intrinsic short penetration distance of UVC light in optically dense protein solutions. This experimental and numerical study establishes that irradiating a fluid flowing continuously in a microfluidic capillary system, in which the diameter of the capillary is turned to the depth of penetration of UVC light, uniquely treats the whole volume of the fluid to UVC light resulting in fast and effective inactivation of pathogens, with particular focus to virus particles. This was demonstrated by inactivating human herpes simplex virus type-1 (HSV-1, a large enveloped virus) on a dense $10 \%$ fetal calf serum solution in a range of fluoropolymer capillary systems, including a $0.75 \mathrm{~mm}$ and $1.50 \mathrm{~mm}$ internal diameter capillaries and a high-throughput MicroCapillary Film with mean hydraulic diameter of 206 $\mu \mathrm{m}$. Up to $99.96 \%$ of HSV-1 virus particles were effectively inactivated with a mean exposure time of up to $10 \mathrm{~s}$, with undetectable collateral damage to proteins. The kinetics of virus inactivation matched well the results from a new mathematical model that considers the parabolic flow profile in the capillaries, and showed the methodology is fully predictable and scalable and avoids both the side effect of UVC light to proteins and the dilution of the fluid in current tubular UVC inactivation systems. This is expected to speed up the industrial adoption of non-invasive UVC virus inactivation in clinical biotechnology and biomanufacturing of therapeutic molecules.
\end{abstract}

Keywords: UVC virus inactivation, microfluidics, microcapillary film, FEP-Teflon, HSV-1, numerical modeling 


\section{Introduction}

The treatment of contaminated fluids with ultraviolet light of wavelength lower than $280 \mathrm{~nm}$ (UVC) has been in practice for few decades, with one of the earliest case studies published by the National Institute of Health in 1949 ( $\mathrm{NIH}, 1949)$. More recently, UVC irradiation showed being effective in inactivating a wide number of pathogens, including bacteria and enveloped and non-enveloped viruses (see for example Caillet-Fauquet et al., 2004; Wang et al., 2004; Li et al., 2004; Bae et al., 2009), consequently UVC irradiation has found a wide range of applications in the healthcare, biopharmaceuticals and water purification sectors. Compared to the more traditional virus removal methods routinely used in the biomanufacturing industry, UVC irradiation has the unique advantages of being non-invasive and allowing continuous processing, yet the short depth of penetration of UVC radiation through dense protein solutions limits the photochemically active region to a thin layer close to the tube walls, generally of few tens or hundreds of microns. Current UVC irradiation devices based on tubular or thin film geometry lack the ability of delivering uniform UVC dosages to the whole volume of the fluid, involving complex design strategies for generation radial mixing or presenting poor control of liquid film thickness, consequently devices are difficult to scale up. Also, the fluid is overexposed resulting in damage to proteins or requiring dilution of the fluid.

A recent study by Wang et al. (2004) showed viral inactivation is caused by UVC-induced damage to viral nucleic acids, being directly linked to the UV dosage or UV fluency $\left(\mathrm{J} \mathrm{cm}^{-2}\right)$ which is linearly proportional to the mean exposure time in the irradiation chamber, $\tau_{\text {mean }}$. As light absorption in the ultra-violet spectrum is not limited to nucleic acids, UVC irradiance can also damage proteins through the generation of reactive chemical species (Streeter and Gordon, 1967). This is regarded as a major barrier for the adoption of UVC viral inactivation technique by the biomanufacturing sector, and results from the difficulty of current UVC irradiation devices in delivering uniform doses of UVC irradiance through optically dense liquid solutions.

In recent years a number of continuous flow UVC irradiation devices were developed and applied to viral inactivation in biopharmaceuticals, plasma and food products (Caillet-Fauquet et al., 2004; Wang et al., 2004; Li et al., 2004; Bae et al., 2009; Koutchma et al., 2006). The early UVC devices often called "laminar thin-film" consisted of irradiating the liquid media in thin films for prolonged time periods, a concept adapted from the photochemistry labs. The difficulty in controlling the film thickness (Wang et al., 2004) and the extremely large irradiation surfaces required to produce the thin films mean these devices are not suited to biological products where high magnitude of viral inactivation of ( $\geq 3 \log _{10}$ units) are normally required.

The latest generation of tubular flow UVC devices uses continuous "turbulent" fluid flow in large-bore fluoropolymer plastic tubing or fused silica tubing, that are either wrapped around a concentric UVC lamp source, with peak emission wavelength, $\lambda=253.7 \mathrm{~nm}$ or placed in parallel to a lamp with a set of mirrors. The reported internal diameters of the tubing are in the range of 5 to $24 \mathrm{~mm}$, representing a significant dead volume of several hundred of millilitres. As UVC irradiation is limited to a thin region near the wall of the tubes, radial mixing of the fluid is generated by means of Dean vortices (Wang et 
al., 2004), or using static mixers (Li et al. 2004). On both cases only a fraction of the fluid is exposed at a given time, which requires extended exposure times typically with several passages in order to fully treat optically thick biological fluids. Consequently, these designs are very difficult to scale up as the secondary mixing is unpredictable. Also, large superficial fluid velocities are required for generating the right extent of radial mixing, and often the fluid is diluted to increase the depth of UVC light penetration.

A more compact design for virus inactivation in blood products was proposed by Laub et at. (2001), consisting of a flow cell built from quartz glass placed at the focal point of a reflectance chamber. Homogeneous flow in the quartz tube is maintained through the use of a baffle or injection of nitrogen, leading to the required level of turbulence in the fluid. As the solution is expose to UVC in a thin layer high levels of reduction in virus titre are achieved at low values of UV fluency $\left(0.001-0.200 \mathrm{~J} \mathrm{~cm}^{-2}\right)$. As this design uses a single capillary fabricated from quartz glass fit within a reflectance chamber the scale-up is unpractical.

This study presents an inexpensive and disruptive non-invasive method for UVC virus inactivation based on fluoropolymer microfluidic capillary systems, in which the inner capillary diameter is tuned to the depth of penetration of the UVC light allowing to fully irradiate the whole volume of the fluid in the capillaries. Contrary to current continuous tubular UVC irradiation devices, the design is fully scalable and governed by well-established physical laws as demonstrated by a new mathematical model which considers the parabolic velocity profiles in the capillaries. By exposing the whole volume of the fluid high reduction factors in virus titre can be achieved using short UV exposure times typically of few seconds. This study is particularly focused on the performance of a new high-throughput fluoropolymer microfluidic material, called MicroCapillary Film (MCF); the application of MCF to rapid photodegradation of emergent contaminants was recently report elsewhere (Reis and Li Puma, 2015), and this study expands the concept to particular theoretical and experimental aspects relevant to virus inactivation. Human herpes simplex virus type-1 (HSV-1) was chosen as the model virus for its wellknown resistance to UVC irradiation (e.g. Croughan and Behbehani, 1988). HSV-1 is a large complex enveloped DNA virus with a genome of $\sim 150 \mathrm{~kb}$, and one of the pathogens more widespread among humans (Ren et al., 2012; Laine et al., 2015). This virus is responsible for non-genital herpes simplex infection, mostly producing cold sores but also responsible for blindness by herpes keratitis (Farooq and Shukla, 2012) and death by herpes simplex encephalitis (Whitley and Kimberlin, 2005). HSV-1 virus particles have an icosahedral capsid surrounded by a layer of protein called tegument and a lipid envelope carrying many viral glycoproteins, which make the virus particles highly resistant to chemical or photochemical inactivation.

\section{Materials and Methods}

\section{Reagents}

Dulbecco's modified Eagle's medium (DMEM) supplemented with 10\% fetal calf serum (FCS), $2 \mathrm{mM}$ L-glutamine, $100 \mathrm{U} \mathrm{ml}^{-1}$ penicillin, and $100 \mathrm{~g} \mathrm{ml}^{-1}$ streptomycin. Glasgow Minimum Essential Medium 
(GMEM) was used as supplied. Purified HSV-1 VP16 and glycoprotein D specific antibody LP11 (McLean et al., 1982) and LP2 (Minson et al., 1986) were donated by T. Minson from the University of Cambridge and used for testing the effect of UVC light on protein/antibody activity by ELISA (protocol as described by Granoff et al., 1998).

\section{Virus and cells}

HSV-1 strain KOS was used in this study. Vero cells were used in plaque assay. To purify KOS, HaCaT cells were infected at 0.01 PFU-per cell and incubated for three days. The culture medium was harvested and centrifuged at 2,000 rpm (Beckman GH3.8) for 20 min to remove cells and debris. The virions in the supernatant were pelleted at 18,000 rpm (Beckman type 19 rotor) for 2 hours, re-

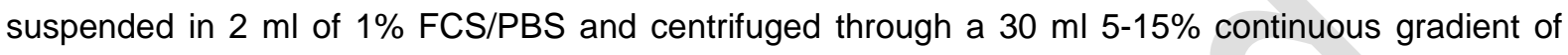
Ficoll 400 in PBS at 12,000 rpm (Beckman SW 32Ti) for 1.5 hours. The clear virus band in the middle of the gradient was harvested, and the virions pelleted at 20,000 rpm (Beckman SW 32Ti) for $2 \mathrm{hr}$. All centrifugations were performed at $4{ }^{\circ} \mathrm{C}$.

\section{Virus titre quantitation}

Virus titres were determined by plaque assay. Vero cell monolayers were infected with the virus containing samples at $37{ }^{\circ} \mathrm{C}$ for one hour, and then overlaid with semisolid medium $(0.6 \%$

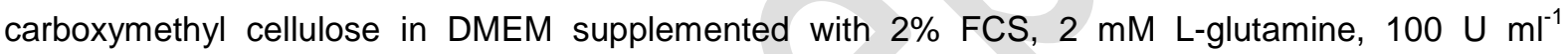
penicillin, and $100 \mathrm{\mu gml}^{-1}$ streptomycin). After incubation at $37^{\circ} \mathrm{C}$ for three days, cells were fixed with $3.7 \%$ formaldehyde in PBS and stained with $0.1 \%$ toluidine blue solution. The plaques were counted

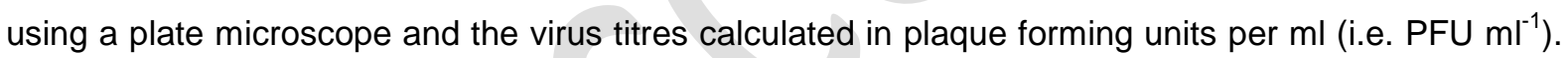
Plaques with diameters smaller than $50 \%$ (or area smaller than $25 \%$ ) were counted as been produced by defective virus particles.

\section{Absorbance of liquid solutions}

The optical densities of a dilution series of FCS in PBS buffer were measured by NanoDrop Spectrophotometer (Thermo Scientific) at $254 \mathrm{~nm}$. The slope of optical density versus concentration of FCS protein in the linear range (up to $25 \%$ FCS) was then taken as the specific absorbance of the solution, $\mathrm{Abs}_{254}\left(\mathrm{~cm}^{-1}\right)$. The specific absorbance estimated from the calibration curve for $10 \% \mathrm{FCS}$ was $\mathrm{Abs}_{254}=13.9 \pm 0.40 \mathrm{~cm}^{-1}$.

\section{Fluoropolymer Microcapillary Film (MCF)}

A 10-bore MCF was manufactured from fluorocarbon fluorinated ethylene polypropylene, FEP-Teflon by Lamina Dielectrics Ltd (Billinghurst, West Sussex, UK) using a melt-extrusion process described by Hallmark et al. (2005a, 2005b). Melt-extrusion is a very cost-effective technique for embedding microengineering features in thermoplastic materials, including fluoropolymers. In the core of the new process lies an injection die composed of an array of hollow needles for air injection/aspiration which is placed at the centre of the polymer melt (Figure 1). This injection die controls the number and size of the microcapillaries, and a set of cooled rolling cylinders draws the film giving a precise control over 
the thickness and width of the plastic material. The MCF used in this study presented a mean internal hydraulic diameter of $206 \pm 12.6 \mu \mathrm{m}$ (Figure 1B), and a mean total (external) film thickness of $534 \pm$ $15.4 \mu \mathrm{m}$. The measured mean distance from the centre of the capillaries to the flat surface of the film was $176 \pm 19.0 \mu \mathrm{m}$, as summarised in Table I. Like other fluoropolymers FEP is characterised by high resistance to solvents, acids and bases, a high light transmittance in VIS-UV wavelengths and a refractive index very close to that of the water (i.e. 1.34). In consequence, there is negligible bending of the photon rays through the curved shape of the capillaries allowing a uniform irradiation of the entire volume of the fluid flowing within the MCF (Reis and Li Puma, 2015).

Some unique features of the MCF are well suited for efficient virus inactivation in optically dense protein solutions, and can be summarised as: i) small internal diameter of microcapillaries, allowing to fully irradiate the whole fluid volume even with optically thick fluids; ii) thin wall thickness, $\delta$ of 100-200 $\mu \mathrm{m}$; iii) melt-extruded from FEP-Teflon, which has as high UVC transmittance and low refractive index; iv) flat surfaces of film, which favours simple designs and effective light penetration from the light source to the film; $v$ ) parallel array of microcapillaries (10 in this study) which can be used for simultaneous photochemical inactivation in multiple solutions or to enhance the required volumetric throughput; vi) easy scale up and customization.

\section{Individual Teflon capillaries}

Experiments were performed in parallel with individual cylindrical capillaries produced from a fluoropolymer material, called poly-tetrafluoroethylene (PTFE, commercially known as Teflon) which has similar properties to FEP-Teflon. Two bore sizes were tested, $749 \mu \mathrm{m}$ ID and 1/16" OD (labelled small bore subsequently), and $1.640 \mu \mathrm{m} \mathrm{ID} \mathrm{and} \mathrm{1/8"} \mathrm{OD} \mathrm{(large} \mathrm{bore).} \mathrm{The} \mathrm{small} \mathrm{bore} \mathrm{capillary} \mathrm{was}$ selected for presenting a total cross section similar to the 10 -bore MCF $\left(0.44\right.$ and $0.33 \mathrm{~mm}^{2}$, respectively), and the large bore capillary presented a cross section $\left(2.11 \mathrm{~mm}^{2}\right)$ and internal diameter about one order of magnitude larger to that of the MCF. All relevant dimensions are summarised in Table I.

\section{UVC inactivation of HSV-1 in plastic microcapillaries}

A compact UVC irradiator was fabricated in-house and consisted of a fully enclosed aluminium box containing a 5W PL-S5 TUC compact fluorescent-germicidal lamp (Lamp Specs, Tolworth, UK), with peak $\lambda=253.7 \mathrm{~nm}$. The compact U-shaped lamp presented a total width of $28 \mathrm{~mm}$ and maximum length of $103 \mathrm{~mm}$. The mean irradiance at the surface of the lamp bulb was $55 \mathrm{~W} \mathrm{~m}^{-2}$. The capillaries were placed at approximately $15 \mathrm{~mm}$ parallel to the centre of the light bulb, and a set of polished stainless steel mirrors was attached to the inner top and bottom surfaces of the box. The mean irradiance at the surface of the capillaries was therefore assumed homogeneous for the entire exposed length of the capillaries. A set of electric fans attached to opposite sides of the microirradiator promoted air circulation keeping temperature constant throughout the experiments; a thermocouple attached to the outer surface of the capillary showed the temperature remained constant within the range $32-34{ }^{\circ} \mathrm{C}$. 
Continuous photochemical virus inactivation experiments were performed by attaching the capillaries to an IVAC P2000 infusion pump (Alaris Medical UK Ltd, Basingstoke, UK) using a female luer-lock connector and standard Upchurch fittings. A 10\% FCS solution was initially infused through the capillaries for few minutes in order to coat the inner walls of the capillaries. FEP is a very hydrophobic polymer and HSV-1 virus particles are extremely infective, therefore being important to block nonspecific adsorption of viral particles directly to the wall of the capillaries. With the UVC lamp switched off, a solution of $10 \%$ FCS spiked with $\sim 1^{\star} 10^{7} \mathrm{PFU} \mathrm{ml^{-1 }}$ of purified HSV-1 was then infused through the capillaries at a constant flow rate as shown in Table I, and samples were collected from the end of the capillaries for virus titre quantitation; this worked as control of (inlet) concentration of infective virus particles in the absence of UVC light. The UVC lamp was then switched on and duplicated samples (>700 $\mu \mathrm{l}$ each) collected for titration directly from the end of the capillary after an initial stabilisation time of 2-3 minutes (i.e. about an order of magnitude larger than the mean residence times tested in the capillary setups). The ratio between the virus titre in the control sample and virus titre in the experiment with UVC light yields the reduction factor (RF) in virus titre; this is demonstrated in further detail in the numerical modelingsection. The virus titre at the outlet of the capillary was consistent after that time period for the whole range of residence times tested. $\tau_{\text {mean }}$ was set by varying the exposed length, $L$ of the capillary to UVC light with black electric tape. By keeping constant the superficial flow velocity, $u_{\text {mean }}$ the effect of $\tau_{\text {mean }}$ on virus titre reduction is decoupled from the residence time distribution or axial dispersion. Three values of $L$ were tested, being 40,80 and $120 \mathrm{~mm}$, corresponding to values of $\tau_{\text {mean }}$ value between 2.5 and 10.0 s (Table II) and UV fluencies of 0.105 to $0.336 \mathrm{~J} \mathrm{~cm}^{-2}$, respectively.

\section{Antibody activity testing}

An antibody containing solution (LP2, $5 \mathrm{ug} / \mathrm{ml}$ ) was pumped through the UVC micro-irradiator using same experimental conditions to virus inactivation trials. Samples collected at different $\tau_{\text {mean }}$ were tested by ELISA. Control experiments were carried out in the absence of UVC light (negative control) and prolonged ( $2 \mathrm{~h}$ ) exposure time (positive control). Antibody activities were calculated as the percentages to the input LP2 (set as 100\%). LP11 (5 ug/ml) was further used as a negative control.

\section{Numerical modeling of viral photo inactivation in microfluidic capillaries}

The kinetics of photochemical viral inactivation in the continuous microfluidic capillary systems were herein modelled based on conventional physical laws that consider light penetration, kinetics of virus inactivation and the parabolic velocity profile in the capillaries. In macroscale photoreactors convective or pure laminar flow is undesirable yielding a very broad distribution of residence times for the fluid, which adds to the poor light penetration (see for example Li Puma and Brucato, 2007; Li Puma, 2003). This mathematical model demonstrates for the first time that the limitations of parabolic velocity profile are overcome by the benefit of irradiating the whole volume of fluid in microfluidic capillaries.

\section{Residence time of virus particles in a capillary}


For fully developed laminar flow in a cylindrical capillary of internal diameter $d_{C}$, the superficial flow velocity $u_{y}$ of a fluid element at an absolute distance $y$ from the centre of the capillary as derived from Navier-Stokes equations is:

$$
u_{y} / u_{\text {mean }}=2\left(1-\left(2 y / d_{c}\right)^{2}\right)
$$

where $u_{\text {mean }}=4 \mathrm{Q}_{\text {in }} / \pi d_{c}^{2}$ is the mean superficial flow velocity, and $Q_{i n}$ is the inlet volumetric flow rate. The mean hydraulic time $\tau_{y}$ for a virus particle flowing along a given fluid-streamline on a capillary with exposed of length $L$ is given by:

$$
\tau_{y}=L / u_{y}
$$

Equations 1 and 2 can be combined yielding:

$$
\tau_{y}=L /\left(2 u_{\text {mean }}\left(1-\left(2 y / d_{c}\right)^{2}\right)\right)
$$

For streamline flow and incident UVC irradiation perpendicular to the surface of the capillary as illustrated in Figure 2A, Equation 3 gives the exposure time of a virus particle flowing along a streamline of length $L$ at radial distance $y$ in the capillary.

\section{UVC light penetration in a circular capillary}

The UV light transmittance through the wall of a capillary, $T_{W}$ can be represented by:

$$
T_{W}=\frac{I_{\text {inner }}}{I_{0}}=\exp \left(-\frac{4 \pi k_{S} \delta}{\lambda \cos \theta_{S}}\right)
$$

where, $k_{S}$ is the extinction coefficient for the wall material (taken as 3.7 based on data available for fluoropolymers from the resins manufacturer, DuPont), $\delta$ is the mean wall thickness $(\mathrm{mm}), I_{0}$ is the UV photon irradiance incident on the outer surface of the capillary, $I_{\text {inner }}$ is the UV photon irradiance at the inner wall of the capillary, and $\theta_{S}$ is the angle of incidence of light in respect to a vector normal to the surface of the capillary. Neglecting the diffuse component of light in the experimental setup, it can be assumed that $\theta_{S}=0^{\circ}$.

The light penetration through the liquid solution was modelled based on Beer-Lambert's law, which considers solution absorbance, $A b s=-\log \left(I_{\text {inner }} /\right)=c \varepsilon l$, with $c$ being the concentration of the absorbing species, $\varepsilon$ the extinction coefficient of the fluid and $\varepsilon$ the light path distance. This can be rearranged yielding the UVC light intensity at the streamline at radial position $y$ :

$$
I_{y}=I_{\text {inner }} \times 10^{(-c \varepsilon \ell)}
$$

with $C$ being also the distance from the streamline to the inner wall therefore having some meaning as in Beer-Lambert's law. Assuming the capillary is homogeneously irradiated (which can be assumed 
for this setup, as the polished stainless steel mirrors present $>85 \%$ reflection and were positioned very close to the UV light source and capillaries), the flow problem can be simplified to 2-dimensional as shown in Figure 2B, and the total photon irradiance at radial position $y$ is:

$$
I_{y} / I_{\text {inner }}=10^{\left(-c \varepsilon \ell_{1}\right)}+10^{\left(-c \varepsilon \ell_{2}\right)}
$$

where $l_{1}$ and $l_{2}$ are light path distances from streamline $y$ to the top and bottom inner walls of the capillary, respectively, which are related to absolute radial position $y$ as follows:

$$
\begin{aligned}
& \ell_{1}=d_{c} / 2-y \\
& \ell_{2}=-d_{c} / 2-y
\end{aligned}
$$

Equations 5 to 7 can be combined to compute the photon irradiance at the fluid streamline $y$ :

$$
I_{y} / I_{\text {inner }}=10^{\left(-c \varepsilon\left(d_{c} / 2-y\right)\right)}+10^{\left.\left(c \varepsilon\left(d_{c} / 2+y\right)\right)\right)}
$$

Equation 8 confirms that for dense solutions $\varepsilon \gg>0$ therefore light can only penetrate a few microns from the wall of the microcapillary and the intensity of transmitted light is highly dependent on the capillary diameter. For clear fluids $\varepsilon \sim 0$, therefore $I_{y} / l_{\text {inner }}=2$, and so the light intensity in the liquid solution is double the photon irradiance reaching the inner wall of the capillary, i.e. $I_{\text {inner }}$, since the 2-D capillary is irradiated from both sides.

\section{Kinetics of viral photoinactivation}

Assuming a conventional $1^{\text {st }}$ order kinetic in virus titre upon exposure to UVC (Roberts and Hope, 2003), the variation of the concentration of infective virus particles, $C_{v}$ during the inactivation time, $t$ is given by:

$$
d C_{V} / d t=-k_{p} C_{V}
$$

where $k_{P}$ represents a UVC photochemical virus inactivation constant $\left(\mathrm{s}^{-1}\right)$, which was considered proportional to the intensity of UVC photon irradiance, i.e. $k_{P} \alpha I$ (see e.g. Wang et al., 2004). The inactivation time, $t$ can be replaced by the hydraulic time, $\tau$ from Equation 2. Equation 9 can then be integrated with the following two boundary conditions:

$$
\begin{aligned}
& \tau=0 \rightarrow C_{V}=C_{V, 0} \\
& \tau=\tau_{y} \rightarrow C_{V}=C_{V, L}
\end{aligned}
$$

Where $C_{V, 0}$ is the virus titre at the inlet or in the absence of UVC light (i.e. control), and $C_{V, L}$ the virus titre at the end of the exposed length of the capillary. Consequently,

$$
-\ln \left(C_{V, L} / C_{V, 0}\right)=k_{P} \tau_{y}
$$


In $\log _{10}$ basis, Equation 11 can be re-written as:

$$
\begin{aligned}
& -\log _{10}\left(C_{V, L} / C_{V, 0}\right)=k_{P} \tau_{y} / 2.30 \\
& \text { or } \quad C_{V, L} / C_{V, 0}=10^{\left(-k_{p} \tau_{y} / 2.30\right)}
\end{aligned}
$$

Equation $12 \mathrm{~b}$ can be applied to a virus particle flowing along a fixed streamline at distance $y$ from centre of the capillary. Taking $k_{p}$ as proportional to $l_{y}$, the ratio $k_{p} / 2.30$ can be replaced by the product $a^{\star} I_{y}$ with "a" being an arbitrary constant (in units of $\mathrm{cm}^{2} \mathrm{~J}^{-1}$ ), yielding:

$$
C_{V, L} / C_{V, 0}=10^{\left(-k_{P} \tau_{y} / 2.30\right)}=10^{\left(-a l_{y} \tau_{y}\right)}
$$

\section{Mean volume-weighted reduction factor in virus titre}

A mass balance to the active virus particles concentration in a thin radial section $d y$ at axial distance $x$ $=L$ of the capillary yields:

$$
d \dot{m}_{V, L}=C_{V, L} \delta Q_{i n}=C_{V, L} u_{y} d y
$$

where $\dot{m}_{V, L}$ is the mass flow rate of infectious viral particles exposed to UVC light. Integrating in respect to $d_{y}$,

$$
\dot{m}_{V, L}=\int_{0}^{d_{c} / 2} C_{V, L} 2 \pi y u_{y} d y
$$

In a similar way, a mass balance to the viral particles entering the capillary, i.e. $x=0$ yields:

$$
\dot{m}_{V, 0}=C_{V, 0} Q_{i n}=C_{V, 0} \pi d_{c}^{2} u_{\text {mean }} / 4
$$

Based on the definition of reduction factor, $1 / R F=\dot{m}_{V, L} / \dot{m}_{V, 0}=C_{V, L} / C_{V, 0}$ it can be shown that the volume-weighted RF in virus titre in the capillary can be calculated with-a simple integration:

$$
1 / R F=8 \int_{y-0}^{y=d_{C} / 2} \frac{C_{V, L}}{C_{V, 0}} \frac{y}{d_{c}^{2}} \frac{u_{y}}{u_{\text {mean }}} d y
$$

Equation 16 was solved numerically by discretising the height of the capillary in 20 fluid streamlines. Experimentally RF is often presented in $\log _{10}$ units, with e.g. $3 \log _{10}$ units corresponding to $99.9 \%$ reduction in virus titre.

\section{Reduction factor in virus titre}

The Bunsen-Roscoe reciprocity law conventionally used to represent the kinetics of virus inactivation states that the magnitude of a photochemical reaction is directly related to the total dose of irradiation that hits the virus particle which is equal to the product of the irradiance to the mean exposure time, 
i.e. UV fluency (Li et al., 2005). This is in agreement with Equation 16, and valid for photochemical reactions in microcapillaries using very short exposure times or reduced UV fluency values. The UVC inactivation experiments with HSV-1 virus particles summarised in Results and Discussion section showed an inactivation kinetics progressing from first order at very low values of $\tau_{\text {mean }}$ to zero order at extended $\tau_{\text {mean }}$ values. This is believed to be linked to the plate assay technique used for counting infective virus particles, to the large genome size of HSV-1 virus, or the intrinsic resistance of these large HSV-1 virus particles to UVC irradiations (as shown by Croughan and Behbehani, 1988) or the tailing effect report elsewhere for other virus particles (see for example Mattle and Kohn, 2012). Such type of kinetics was numerically solved by discretising Equation 16 also along the axial distance $x$ with a small $\left(5 \mathrm{~mm}\right.$ ) spacing from 0 to $L$ and setting a minimum value for $C_{V, L} / C_{V, O}$ (or maximum $\log _{10} R F$ ) that could be achieved in the capillary; that value was based on experimental runs and fitting of numerical model to the data as detailed in Results and Discussion section.

\section{Results and Discussion}

\section{Modeling of UVC light penetration in plastic capillaries}

It is well established in literature that the performance of a photoreactor is extremely dependent on the depth of light penetration. This study aimed at establishing that the diameter of fluoropolymer capillaries can be tuned to the penetration distance of UVC light in dense biological fluid allowing to fully irradiate the whole volume of fluid. This is highlighted in Equation 8, which shows light penetration through dense protein solutions is very dependent on the internal diameter of the capillary in addition to the absorbance of the fluid. This is evaluated by the microcapillary optical thickness (Equation 17), which has similar physical meaning to $A b s_{254}$ in Equation 5 and corresponds to the product of $d_{C}$ to the solution extinction coefficient and the concentration of the absorbing species:

$$
\text { Optical thickness }=c \varepsilon d_{c}
$$

The value of $A b s_{254}$ measured for the running $10 \%$ FCS solution was $13.4 \mathrm{~cm}^{-1}$, which yields $90 \%$ light depletion (i.e. $1 \log _{10}$ unit reduction in I) for a distance of $\sim 746 \mu \mathrm{m}$. This means for effective inactivation of viruses in optically dense solutions very small values of $d_{C}$ are required. As shown in Figure 3-the radial profile of the normalised light intensity $I_{y} / I_{0}$ for the three different fluoropolymer microfluidic systems tested shows a very pronounced depletion of light towards the centre of the capillary as $d_{C}$ increases, since the optical thicknesses of the small bore (Figure $3 \mathrm{~B}$ ) and large bore (Figure $3 C$ ) individual capillaries were 1.00 and 2.20 , respectively. In contrast, $I_{y} / I_{0}$ remains very uniform across the whole cross section (or volume) for the $206 \mu \mathrm{m}$ MCF system with an optical thickness of 0.28 (Figure $3 \mathrm{~A}$ ). These simulations required best-fitting a single arbitrary parameter, $a$ $\left(\mathrm{cm}^{2} \mathrm{~J}^{-1}\right)$ in Equation $12 \mathrm{c}$ based on minimum squares difference for each capillary system; values used in the model are summarised in Table I.

As expected, the parabolic velocity profile in the capillaries results in significant differences in the exposure time of viral particles flowing along difference distances from the walls of the capillary. The 
$\mathrm{RF}$ in active virus concentration as estimated by the model is plotted in Figure 3-and shown as the ratio $C_{V, L} / C_{V, O}$. This was found highly dependent on both the optical properties of the microflow system and $d_{C}$. Higher values of RF (and lower values of $C_{V, L} / C_{V, 0}$ ) were-obtained in the MCF (Figure $3 \mathrm{~A}$ ) using much shorter capillary lengths compared to the small bore (Figure 3B) and large bore (Figure 3C) individual capillaries. It is particularly remarkable the extended exposed lengths required in the small and large bore individual capillaries to yield e.g. $3 \log _{10}$ units reduction in $C_{V, L} / C_{V, 0}$ at the centre the capillaries which results from the reduced UVC light intensity and shortest residence time for virus particles traveling in the centre of the capillary (Li Puma and Brucato, 2007; Li Puma, 2003). This is the typically situation in macroscale photoreactors, and clearly the use of smaller capillaries is highly beneficial to the design of UVC treatment devices.

\section{Experimental UVC photochemical inactivation of purified HSV-1 virus in the capillary systems}

Continuous UVC inactivation trials with $10 \%$ FCS spiked with $10^{7}$ PFUs $\mathrm{ml}^{-1}$ of purified human HSV-1 virus revealed major differences in the kinetics of viral inactivation in the three different fluoropolymer microfluidic capillary systems tested (Figure 4), operated at similar values of $u_{\text {mean }}$ (Table I). The maximum value of $\log _{10} R F$ in virus titre obtained was 3.39 for the range of $\tau_{\text {mean }}$ tested, corresponding to $\approx 99.96 \%$ reduction in virus titre. Note that percentage reduction in virus titre can be converted to RF using the equation:

$$
\% \text { reduction }=\left[1-\frac{1}{R F}\right] \times 100
$$

The smallest capillaries in the MCF (with $d_{c}=206 \mu \mathrm{m}$ ) yielded a $\log _{10} \mathrm{RF}=2.80 \pm 0.270$ for a $\tau_{\text {mean }}=$ $3.2 \mathrm{~s}$, which represents about a $2 \log _{10}$ units improvement in comparison with the maximum RF obtained with-in larger individual fluoropolymer capillaries. An increase in $L$ or $\tau_{\text {mean }}$ resulted in a $\log _{10} R F$ of up to 3.39 in the MCF and 3.35 for the small-bore individual capillary (bore size, $d_{C}=0.749$ $\mathrm{mm})$. In contrast, the maximum $\log _{10} R F$ obtained with the large-bore capillary $\left(d_{C}=1.640 \mathrm{~mm}\right.$ ) was 2.39, so up to $1 \log _{10}$ unit lower than the RF obtained in the smallest capillaries tested. The difference in the RF is less significant at extended exposure time since the maximum RF of the virus is approached (less than 4, Table I). The values of RF obtained were similar to those reported by e.g. Croughan and Behbehani (1988) yet using approx. 20 times shorted exposure times; those authors reported $\log _{10} R F=3.5$ with 3 min exposure to UVC.

Overall, the kinetics of photochemical inactivation of HSV-1 in the capillary systems appeared to be of first order for the lowest values of $\tau_{\text {mean }}$ used, however, the reaction rate decreased as $\tau_{\text {mean }}$ increased. Experiments carried out with longer $\tau_{\text {mean }}$ of up to $45 \mathrm{~s}$ showed the maximum $\log _{10} \mathrm{RF}$ did not increase further with the increase in exposure time (results not shown). This is similar to what has been reported by Croughan and Behbehani (1988), whom reported UVC failed to completely inactivate HSV particles in $15 \mathrm{~min}$. The numerical model fitted well the experimental data based on a single arbitrary parameter, a assuming a-maximum $\log _{10} R F=3.5$ (Table I). The continuous lines in Figure 4 show best fitted numerical model results, and experimental data shown by the symbols. This 
demonstrates-photochemical inactivation of viruses in microcapillaries is fully predictable and scalable despite the capillary systems operate in laminar flow regimes. The values of arbitrary parameter found were 25, 30 and $90 \mathrm{~cm}^{2} \mathrm{~J}^{-1}$ for the MCF, small bore capillary and large bore capillary, respectively as summarised in Table I, which reveals light penetration is more effective in small diameter capillaries and in particular in flat capillary films.

\section{Defective HSV-1 virus particles in the MCF}

A detailed analysis to the plaque assays of the samples UVC treated on each microflow system revealed a large ratio of small plaques (small white spots) to large plaques (large white spots) in the samples processed in the MCF (Figure $5 \mathrm{~A}$ ) which could not be mimicked in other capillary systems (data not shown). The size of the small and large spots was visually very distinct, and easy to differentiate with a plate microscope. Plaques with diameters smaller than 50\% (or area smaller than 25\%) were counted as been produced by defective virus particles (i.e. small spots). The ratio of number of small plaques to total plaques, herein designated as $\alpha$ is also summarised-in Figure $5 \mathrm{~A}$ and revealed a large fraction of defective viruses especially in the samples exposed for the-shortest $\tau_{\text {mean }}$. This is relevant as it shows the extent of effective damage to HSV-1 virus particles is larger than the one represented by the $\log _{10} \mathrm{RF}$ values shown in Figure 4 . For example, for a value of $\tau_{\text {mean }}=2.5 \mathrm{~s}$ about $99.84 \%$ of virus particles were fully inactivated (Figure 4 ), yet $86.6 \%$ of virus particles that remained infective to cells were defective. This is believed to be related to the unique optical properties of the MCF material which favours a more effective UVC light penetration through the microcapillary walls.

\section{Undetectable protein damage in microfluidic capillary systems}

UVC irradiation is well known to induce photo-damage to proteins in biopharmaceutical products (see for example Chan et al., 2006). This is a paramount aspect when designing a UVC treatment unit which aims maximizing the extent of virus inactivation whilst minimizing collateral damage of UVC such as reduction in biological activity of the bioproduct. In order to demonstrate reduced UVC exposure in capillary systems helps minimising side effects of UVC treatment further experiments were carried out with the same 10\% FCS solution spiked with LP2 (positive control) and LP11 (negative control) antibodies in the presence and absence of UVC light (Figure 5B). The antibody activity assessed by ELISA revealed $>90 \%$ reduction in LP2 antibody activity for very long UVC exposure times ( $2 \mathrm{~h}$ used as control) yet no reduction in antibody activity could be detected at the same experimental conditions used for UVC inactivation of HSV-1 in the capillary systems.

\section{Numerical prediction of $\log _{10}$ RF of HSV-1 virus titre in optically thick fluids}

Microfluidic capillary systems uniquely offer the possibility of tuning $d_{c}$ to the optical thickness or light penetration distance in the biological fluid whilst irradiating the whole volume of the fluid. The potential applications of this new method are vast and include clinical manufacturing, bioproduction of therapeutic molecules, food sterilisation and even possibly blood donation. In order to guarantee an effective sterilisation, the optical thickness should be kept smaller than 1 as shown in Figure 6B, 
representing a maximum $90 \%$ reduction in light penetration. This is conventionally done in tubular UVC treatment units by diluting the sample, which presents several drawbacks such as increasing the volume to be processed and reducing the protein loading for chromatographic processes. The impact of $d_{c}$ on RF for HSV-1 particles in the fluoropolymer MCF was therefore modelled for a wide range of fluid absorbances or optical thickness, which cover the all possible range of $A b_{254}$ measured for $10 \%$ FCS $\left(\right.$ Abs $\left._{254}=13.4 \mathrm{~cm}^{-1}\right)$, plasma $\left(\mathrm{Abs}_{254}=20.0 \mathrm{~cm}^{-1}\right)$ and whole blood $\left(\mathrm{Abs}_{254}=618.0 \mathrm{~cm}^{-1}\right)$. The model predicted similar performance in 10\% FCS and undiluted plasma for a range of $d_{c}$ up to 200$500 \mu \mathrm{m}$, and surprisingly $>99.9 \%$ inactivation or $3 \log _{10}$ units in RF in whole blood using a value of $d_{c}$ in the range of $10-15 \mu \mathrm{m}$ (Figure $6 \mathrm{~A}$ ). This is yet to be demonstrated in future studies; whole blood is a colloidal solution presenting a large barrier to light penetration that cannot be treated with the current UVC tubular inactivation technology. The small volume of plastic capillaries offers the possibility of treating a small clinical/bioanalytical sample volume, being easily scaled up by using a bunch of parallel capillaries; this design aspects are further discussed below. In particular, the meltextrusion processed used for the production of MCF is capable of precisely producing capillaries having $d_{c}$ in the range of few microns.

\section{Design approaches for scale-up of capillary UVC virus inactivation systems}

Plastic fluoropolymer capillaries are widely available in a range of $d_{c}$ with excellent UVC transmittance. Fluoropolymers like FEP-Teflon, PTFE and PFA show a transmittance $>80 \%$ in the UVC wavelength according to the manufacturer, DuPont which is unmatched by other conventional polymeric microfluidic devices fabricated from e.g. PDMS, PDMA, COC, which show poor transmittance in the short UV. Plastic capillaries including MCFs are mass manufactured and flexible therefore suited to the fabrication of compact, modular devices for non-invasive inactivation of virus similar using similar setups to hollow-fibre, microfiltration or hemodialysis units. The low cost of the material also potentials disposability which is a current trend and need in biomanufacturing. Fluoropolymers are inert therefore FDA approved for several medical applications. The shape and geometry of MCF capillary array is ideally suited to larger throughputs for containing a large number of parallel capillaries that can be easily connected to other bioprocessing equipment, consequently offering the possibility to design portable units for UVC virus inactivation in a wide range of throughputs. This might include sterilising few microliters/mililiters of a clinical sample in a research and development lab or up to $1 \mathrm{~m}^{3} / \mathrm{h}$ in industrial biomanufacturing plants using just few meters of length of material. The volume and pressure drop can be balanced by varying the internal diameter and/or the total length of the capillaries. Note that pressure drop in capillaries is easily predictable based on Hagen-Poiseulle's equation.

As a possible design scenario, taking a 10-bore MCF with $d_{c}=0.5 \mathrm{~mm}$ and exposed length of 100 $\mathrm{mm}$ (corresponding to $10 \mathrm{~s}$ exposure time) the volumetric flow rate obtained would be $\sim 1.96 \mathrm{ml} \mathrm{s}^{-1}$ or $7.1 \mathrm{~L} \mathrm{~h}^{-1}$. The liquid throughput could be increased to $0.7 \mathrm{~m}^{3} \mathrm{~h}^{-1}$ yielding $\sim 17.0 \mathrm{~m}^{3}$ of fluid sterilised in a $24 \mathrm{~h}$ shift, based on a bundle of 100 MCF strips running in parallel. The total length of MCF material 
required would be $10 \mathrm{~m}$ with a projected material cost of 10-100 pounds sterling. The total inner volume of the capillaries would be $19.6 \mathrm{ml}$, and the footprint of the unit smaller than $0.1 \mathrm{~m}^{2}$.

Figure 7 shows three possible compact design strategies for scaling-up UVC irradiation based on MCFs. A single MCF strip can be wrapped around a tubular UVC lamp (Figure 7A), being ideal for processing a small volume of a fluid such as a biological analytical or clinical sample. Alternatively, multiple MCF strips connected to a manifold can be placed in parallel around a tubular lamp (Figure 7B). To achieve the throughputs required by e.g. biomanufacturing plants, parallel MCF strips can be welded in multiple sheets and sandwiched between multiple layers of tubular UVC lamps to deliver homogeneous fluencies in the entire volume of the unit (Figure 7C).

In addition to the good UVC inactivation performance revealed by the microfluidic MCF material, the excellent heat transfer performance of this material (see e.g. Hornung et al., 2006) offers the opportunity of coupling non-invasive photochemical UVC with well-established heat treatment for achieving larger RF in virus titre.

\section{Conclusions}

This experimental and numerical study showed that UVC inactivation of human HSV-1 in an optically dense protein solution is fast and efficient in small diameter microfluidic capillary systems fabricated from fluoropolymers. The new numerical model presented revealed $d_{c}$ and optical thickness are the two critical design parameters which determine the overall kinetics of photochemical inactivation in a fully developed laminar flow by controlling the light penetration depth. Contrary to large bore tubular systems, the UVC irradiation in microcapillaries is fully scalable and based on simple well-established physical laws, including Beer-Lambert's law for UVC light penetration, and the parabolic velocity profile. The geometry and optical properties of fluoropolymer MCF material favours higher and faster reduction factors in virus titre compared to individual cylindrical capillaries. The new method is scalable, non-invasive and applicable to the inactivation of a range of pathogens, including bacteria and both enveloped and non-enveloped virus particles with undetectable damage to proteins in the opaque fluid. Future studies will extend this work to the inactivation of other virus systems and sterilisation of relevant biological fluids, including plasma and whole blood.

\section{Acknowledgements}

The authors would grateful to Patrick Hester from Lamina Dielectrics Ltd for donating the MCF material, and Professors Zhanfeng Cui and Nigel Slater for encouragement in carrying out this work. Nuno Reis is grateful to European Commission Marie Curie IEF programme (project 221768) for financial support. Yudan Ren is grateful to Cambridge Overseas Trust, Robinson College, the Board of Graduate Studies, and the Department of Pathology at the University of Cambridge. Colin Crump also acknowledges financial support from The Royal Society (UF090010).

\section{References}


Bae JE, Eun KJ, Jae IL, Jeong IL, In SK, Jong-su K. 2009. Evaluation of Viral Inactivation Efficacy of a Continuous Flow Ultraviolet-C Reactor (UVivatec). Korean Journal of Microbiological Biotechnology 37(4):377-382.

Caillet-Fauquet P, Di Giambattista M, Draps ML, Sandras F, Branckaert T, de Launoit Y, Laub R. 2004. Continuous-flow UVC irradiation: a new, effective, protein activity-preserving system for inactivating bacteria and viruses, including erythrovirus B19. Journal of Virological Methods 118:131139.

Chan H-L, Gaffney PR, Waterfield MD, Anderle H, Matthiessen HP, Schwarz H-P, Turecek PL, Timms JF. 2006. Proteomic analysis of UVC irradiation-induced damage of plasma proteins: Serum amyloid $\mathrm{P}$ component as a major target of photolysis. FEBS Letters 580(13):3229-3236.

Croughan WS, Behbehani AM. 1988. Comparative Study of Inactivation of Herpes Simplex Virus Types 1 and 2 by Commonly Used Antiseptic Agents. Journal of Clinical Microbiology 26(2):213-215.

Farooq AV, Shukla D. 2012. Herpes simplex epithelial and stromal keratitis: an epidemiologic update. Surv. Ophthalmol. 57, 448-462.

Granoff DM, Maslanka SE, Carlone GM, Plikaytis BD, Santos GF, Mokatrin A., Raff HV. 1998. A Modified Enzyme-Linked Immunosorbent Assay for Measurement of Antibody Responses to Meningococcal C Polysaccharide That Correlate with Bactericidal Responses. Clinical and Diagnostic Laboratory Immunology, 5(4):479-485

Hallmark B, Gadala-Maria F, Mackley MR. 2005. The melt processing of polymer microcapillary film (MCF). J. Non-Newtonian Fluid. Mech. 128:13-28.

Hallmark B, Mackley MR, Gadala-Maria F. 2005. Hollow Microcapillary Arrays in Thin Plastic Films. Adv. Eng. Mater. 7(6):545-547.

Hornung $\mathrm{CH}$, Hallmark B, Hesketh RP, Mackley MR, 2006. The fluid flow and heat transfer performance of thermoplastic microcapillary films. J. Micromech. Microeng. 16:434-447.

Koutchma T, Parisi B, Unluturk SK. 2006. Evaluation of UV dose in flow-through reactors for fresh apple juice and cider. Chemical Engineering Communications 193(6): 715-728.

Laine RF, Albecka A, van de Linde S, Rees EJ, Crump CM, Kaminski CF. 2015. Structural analysis of herpes simplex virus by optical super-resolution imaging. Nat Commun. 22(6):5980.

Li Puma G, Brucato A. 2007. Dimensionless analysis of slurry photocatalytic reactors using two-flux and six-flux radiation absorption-scattering models. Catalysis Today 122 (1-2):78-90.

Li Puma G. 2003. Modelling of Thin-Film Slurry Photocatalytic Reactors Affected by Radiation Scattering. Environmental Science and Technology 37 (24): 5783-5791.

Mattle MJ, Kohn T. 2012. Inactivation and Tailing during $\mathrm{UV}_{254}$ Disinfection of Viruses: Contributions 
of Viral Aggregation, Light Shielding within Viral Aggregates, and Recombination. Environ. Sci. Technol. 46:10022-10030.

McLean C, Buckmaster A, Hancock D, Buchan A, Fuller A, Minson A. 1982. Monoclonal antibodies to three non-glycosylated antigens of herpes simplex virus type 2. J. Gen. Virol. 63:297-305.

Minson AC, Hodgman TC, Digard P, Hancock DC, Bell SE, Buckmaster EA. 1986. An analysis of the biological properties of monoclonal antibodies against glycoprotein $D$ of herpes simplex virus and identification of amino acid substitutions that confer resistance to neutralization. J Gen Virol. 67:100113.

National Institutes of Health: Minimum Requirements: Normal Human Plasma, rev 6. Bethesda, Department Health Education \& Welfare, 1949.

Qiangyi Li, Shirley MacDonald, Carol Bienek, Peter R. Foster, Alex J. MacLeod. 2005. Design of a UV-C irradiation process for the inactivation of viruses in protein solutions. Biologicals 33:101-110.

Reis NM, Li Puma G. 2015. A novel microfluidic approach for extremely fast and efficient photochemical transformations in fluoropolymer microcapillary films. Chem. Commun., 51: 8414-8417

Ren Y, Bell S, Zenner HL, Lau SYK, Crump CM. 2012. Glycoprotein M is important for the efficient incorporation of glycoprotein H-L into herpes simplex virus type 1 particles. J. Gen. Virol. 93: 319-329.

Roberts $P$, Hope A, 2003. Virus inactivation by high intensity broad spectrum pulsed light, Journal of Virological Methods, 110(1): 61-65

Ross LJN, Wildy P, Cameron KR. 1971. Formation of small plaques by herpes viruses irradiated with ultraviolet light, Virology 45:808-812.

Streeter DG, Gordon MP. 1967. Ultraviolet photoinactivation studies on hybrid viruses obtained by the cross-reconstitution of the protein and RNA components of $U(1)$ and $U(2)$ strains of TMV. Photochem Photobiol 6:413-421.

Wang J, Mauser A, Chao S.-F., Remington K, Treckmann R, Kaiser K, Pifat D, Hotta J. 2004. Virus inactivation and protein recovery in a novel ultraviolet-C reactor. Vox Sanguinis 86:230-238.

Whitley RJ, Kimberlin DW. 2005. Herpes simplex encephalitis: children and adolescents. Semin. Pediatr. Infect. Dis. 16:17-23. 


\section{Tables}

Table I. Dimensions and properties of microfluidic capillary systems and parameters used in the numerical model

\begin{tabular}{|c|c|c|c|c|}
\hline Definition & $\begin{array}{l}\text { Parameter } \\
\text { [units] }\end{array}$ & MCF & $\begin{array}{l}\text { Small bore } \\
\text { capillary }\end{array}$ & $\begin{array}{l}\text { Large bore } \\
\text { capillary }\end{array}$ \\
\hline Inlet flow rate, & $Q_{\text {in }}\left[\mathrm{ml} \mathrm{hr}^{-1}\right]$ & 15.0 & 19.8 & 99.9 \\
\hline $\begin{array}{l}\text { Mean superficial flow velocity (defined as the } \\
\text { ratio of flow rate to cross section) }\end{array}$ & $u_{\text {mean }}\left[\mathrm{mm} \mathrm{s}^{-1}\right]$ & 12.5 & 12.5 & 13.1 \\
\hline Number of bores & $n[-]$ & 10 & 1 & 1 \\
\hline Internal diameter of capillary & $d_{c}[\mathrm{~mm}]$ & $\begin{array}{c}0.206 \\
( \pm 0.012)\end{array}$ & 0.749 & 1.640 \\
\hline Open cross section $\left(=\pi / 4^{\star} d_{c}^{*} n\right)$ & $-\left[\mathrm{mm}^{2}\right]$ & 0.33 & 0.44 & 2.11 \\
\hline Thickness of capillary wall & $\delta[\mathrm{mm}]$ & $\begin{array}{c}0.176 \\
( \pm 0.019)\end{array}$ & 0.419 & 0.768 \\
\hline Optical thickness & {$[-]$} & 0.286 & 1.041 & 2.280 \\
\hline $\begin{array}{l}\text { UV photon irradiance incident on the inner } \\
\text { wall of the capillary }\end{array}$ & $I_{\text {inner }}\left[\mathrm{W} \mathrm{cm}^{-2}\right]$ & 0.032 & 0.031 & 0.028 \\
\hline Arbitrary constant & $a\left[\mathrm{~cm}^{2} \mathrm{~J}^{-1}\right]$ & 25 & 30 & 90 \\
\hline $\begin{array}{l}\text { UV photon irradiance incident on the outer } \\
\text { surface of the capillary }\end{array}$ & $I_{0}\left[\mathrm{~W} \mathrm{~cm}{ }^{-2}\right]$ & & 0.035 & \\
\hline UV light transmittance of the capillary wall & $T_{W}[-]$ & & 0.97 & \\
\hline $\begin{array}{l}\text { Extinction coefficient of the capillary wall } \\
\text { material }\end{array}$ & $k_{S}[-]$ & & 3.7 & \\
\hline UVC wavelength & $\lambda[\mathrm{nm}]$ & & 253.7 & \\
\hline Absorbance of solution (Abs $=c \varepsilon \varepsilon l_{,}$) & $\mathrm{Abs}_{254}\left[\mathrm{~cm}^{-1}\right]$ & & $13.9 \pm 0.40$ & \\
\hline Angle of incident light & $\theta_{S}[$ degrees] & & 0 & \\
\hline Maximum $\log _{10} R F$ & {$[-]$} & & 3.50 & \\
\hline
\end{tabular}


Table II. Experimental conditions used in the HSV-1 virus inactivation trials

\begin{tabular}{lccc}
\hline & \multicolumn{3}{c}{$\tau_{\text {mean }}[\mathrm{s}]$} \\
\cline { 2 - 4 } Microflow system & $L=40 \mathrm{~mm}$ & $L=80 \mathrm{~mm}$ & $L=120 \mathrm{~mm}$ \\
\hline $\begin{array}{l}\text { Small-bore plastic } \\
\text { capillary }\end{array}$ & 3.2 & 6.4 & 9.6 \\
$\begin{array}{l}\text { Large-bore plastic } \\
\text { capillary }\end{array}$ & 3.0 & 6.1 & 9.1 \\
\begin{tabular}{l} 
MCF \\
\hline
\end{tabular} & 3.2 & 6.4 & 9.6 \\
\hline
\end{tabular}




\section{Figure captions}

Figure 1. Plastic microcapillary films. (A) Melt-extrusion processed used in the continuous fabrication of fluoropolymer MCF. (B) Cross-section the MCF used in the continuous-UVC microflow inactivation of HSV-1.

Figure 2. Fluid mechanics and light penetration in a 2D microcapillary. (A) Parabolic velocity profile based on Navier-Stokes equation. (c) Modeling of UVC light intensity in the capillaries based on BeerLambert's law.

Figure 3. Modeling of light penetration, $I_{y} / I_{0}$ and reduction in active virus particles concentration, $C_{V, L} / C_{V, O}=1 / R F$ in the capillary systems. (A) MCF; (B) small bore capillary; (C) large bore capillary. This was based on $\mathrm{Abs}_{254}=13.9 \mathrm{~cm}^{-1}$ corresponding to $10 \% \mathrm{FCS}$.

Figure 4. Effect of $\tau_{\text {mean }}$ on $\log _{10} \mathrm{RF}$ in HSV-1 active virus titre in the capillary systems. Dots represent experimental data, and lines represent best-fitted numerical model. The error bars corresponds to one mean standard deviation calculated from 4 experimental replicas. Error bars represent two standard deviations of three experimental replicas.

Figure 5. Defective virus and protein damage upon exposure to UVC treatment. (A) Ratio of defective HSV-1 virus particles obtained in the continuous-UVC virus inactivation experiments in the MCF as shown in Figure $4 ; \alpha$ represents the ratio of small plaques (small white spots) to total number of plaques, and $n$ the total number of spots measured. (B) LP2 and LP11 antibody activity tests in the capillary systems. Error bars represent two standard deviations of three experimental replicas.

Figure 6. Modeling of effect of $d_{c}$ and optical thickness on the $\log _{10} R F$ in HSV-1 virus titre. This is based on parameters best-fitted to HSV-1 virus inactivation in the MCF and $\tau_{\text {mean }}=9.6 \mathrm{~s}$. (A) $\log _{10} \mathrm{RT}$ predicted with the numerical model for a range of fluid $\mathrm{Abs}_{254}$ values overlapped with experimental data from Figure 4 for the different capillary systems. (B) The effect of both $d_{c}$ and $A^{-b s_{254}}$ is jointly considered by the optical thickness in Equation 17, yielding an universal prediction for $\log _{10} R F$ in HSV-1 virus titre.

Figure 7. Some possible designs for UVC irradiation devices based in MCFs, suited to a range of throughputs and applications. 
List of Figures

A

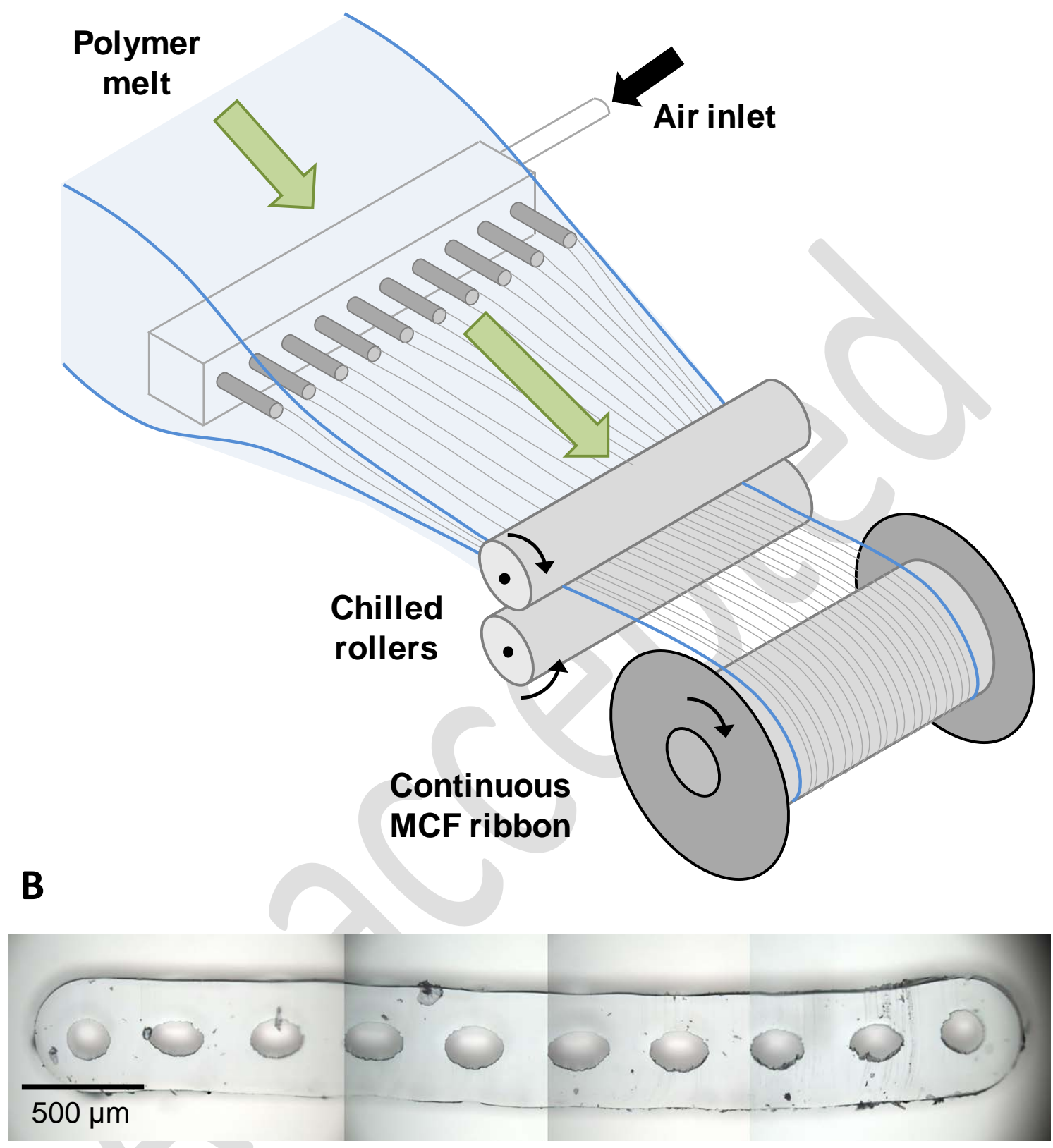

Figure 1 


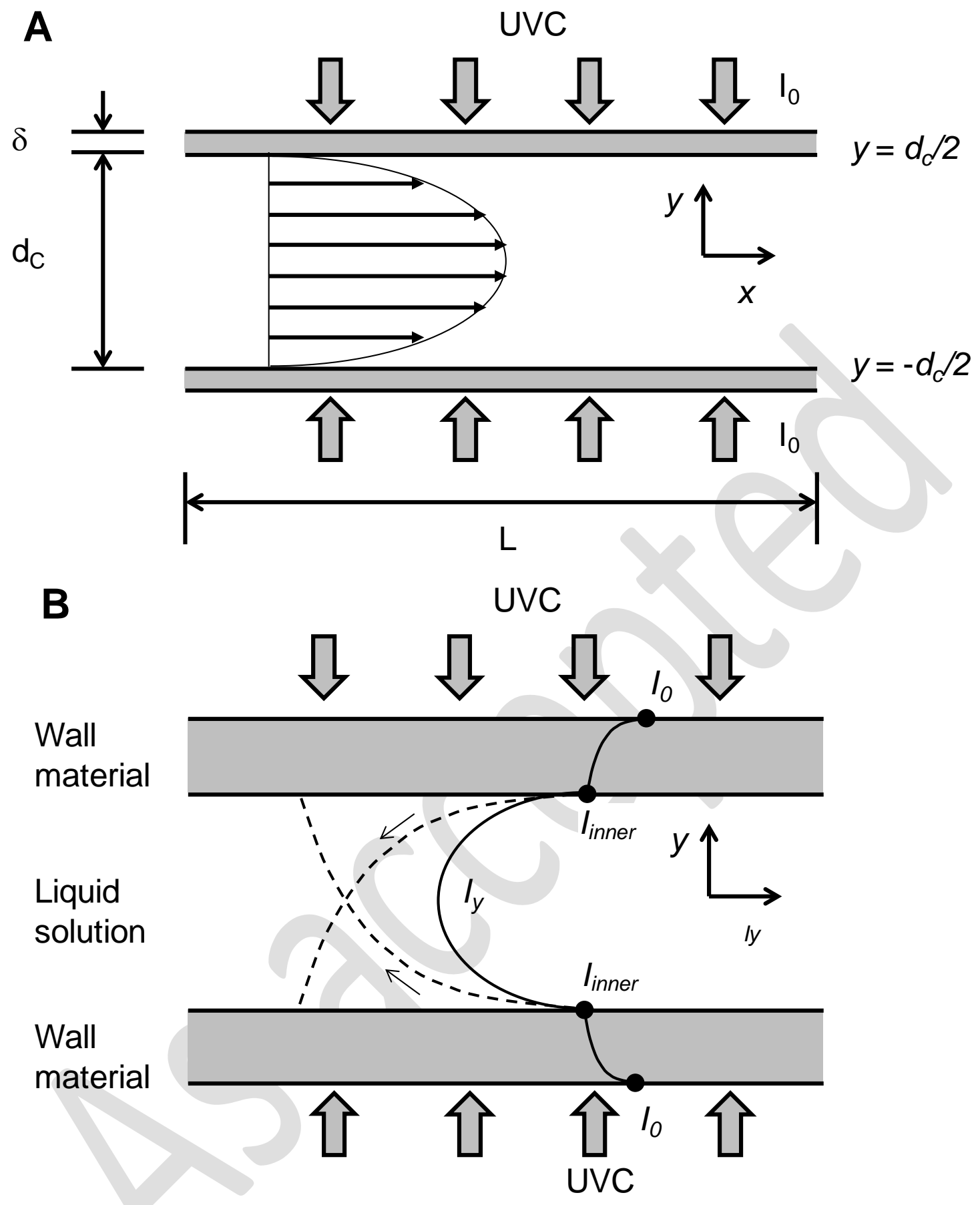

Figure 2 

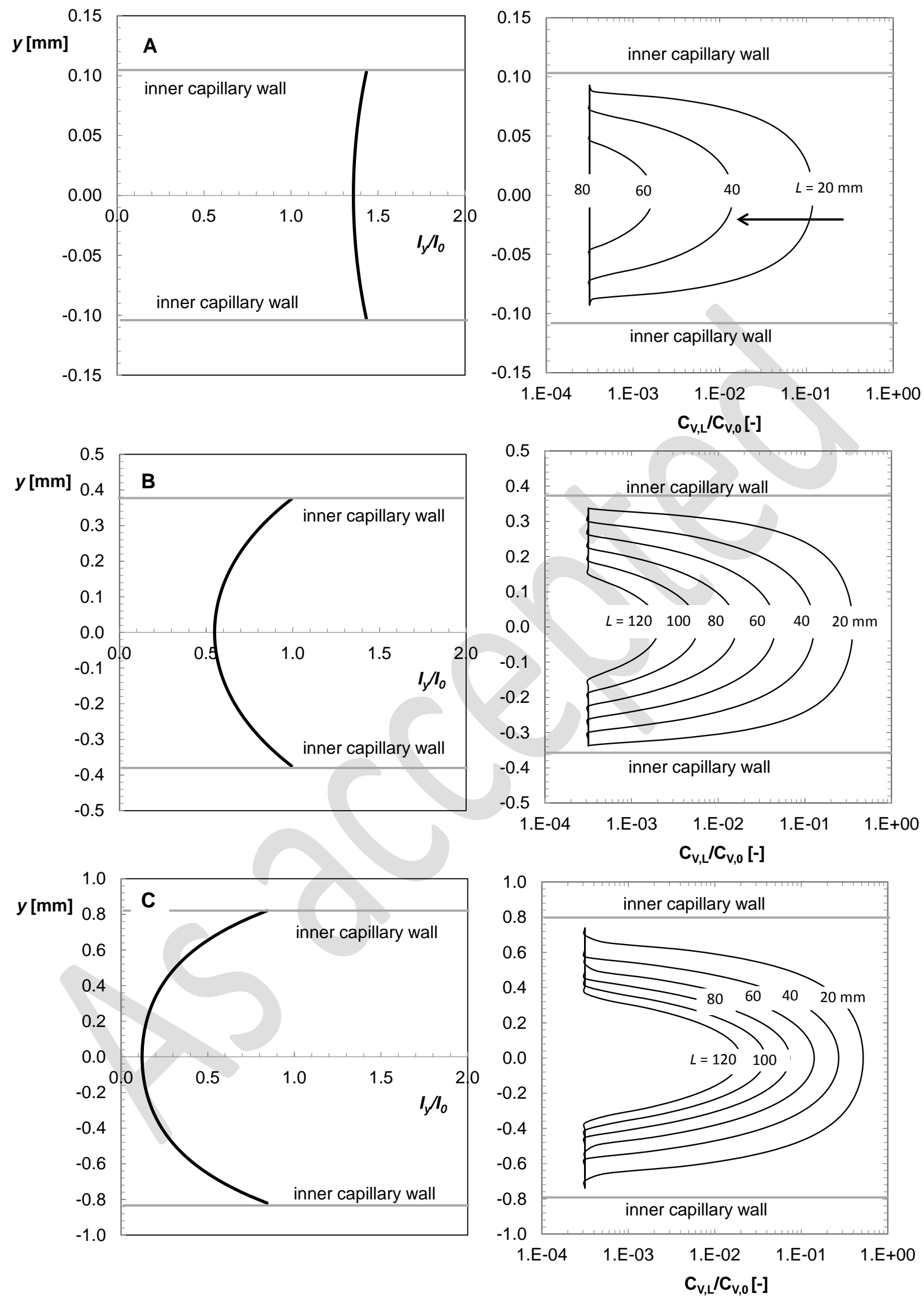

Figure 3 


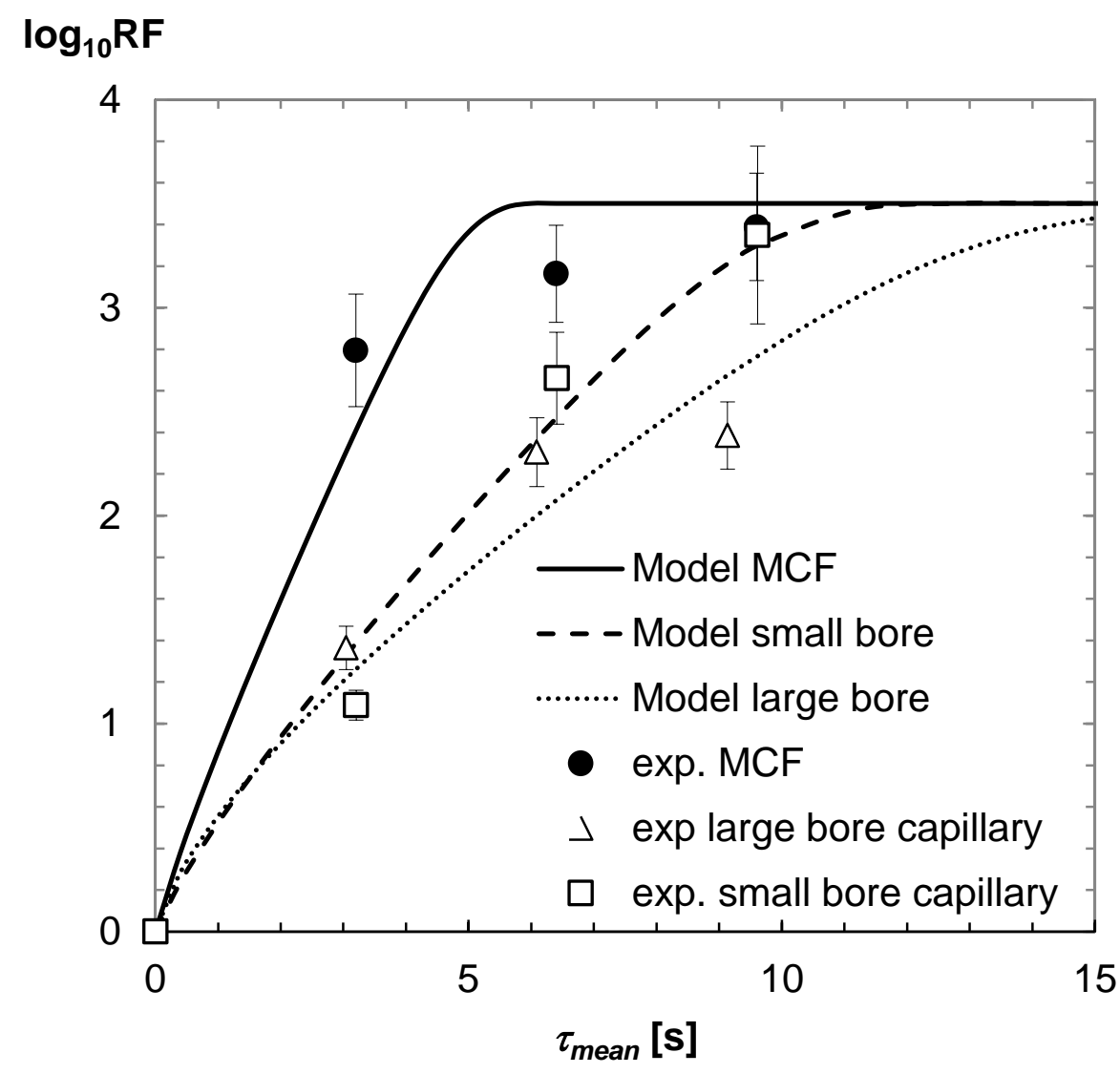

Figure 4 
A
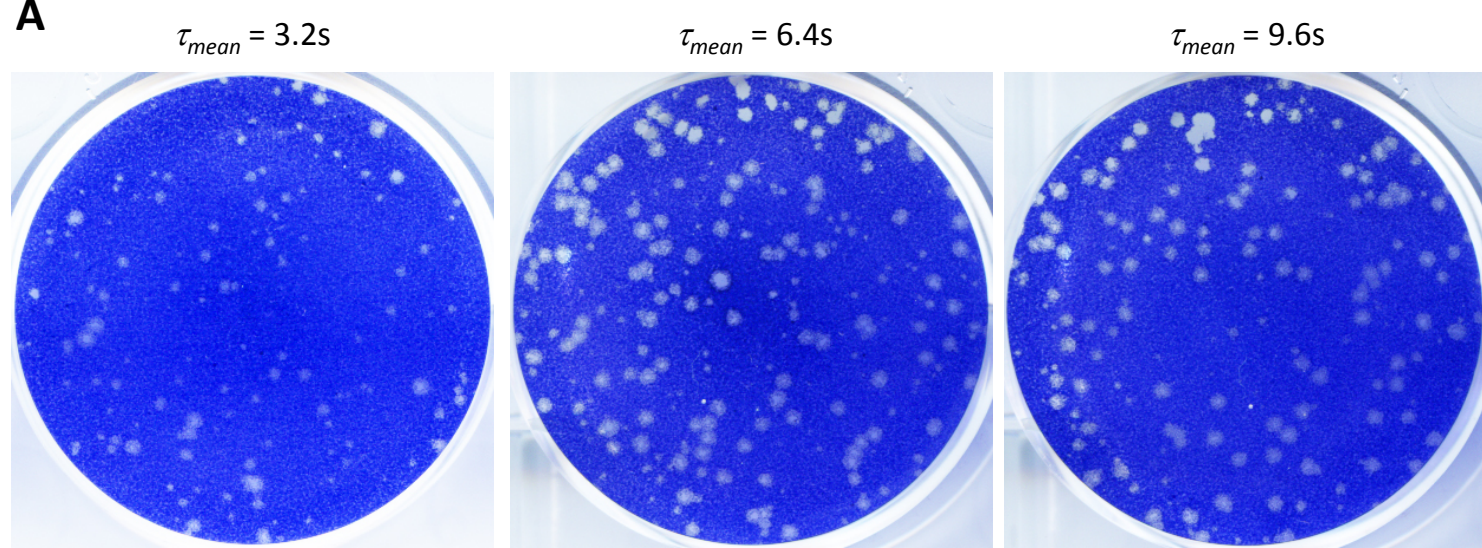

$$
\begin{aligned}
& \alpha=86.6 \% \\
& (n=320)
\end{aligned}
$$

$$
\alpha=41.2 \%
$$

( $\mathrm{n}=286)$

$$
\begin{aligned}
& \alpha=29.5 \% \\
& (n=508)
\end{aligned}
$$

B

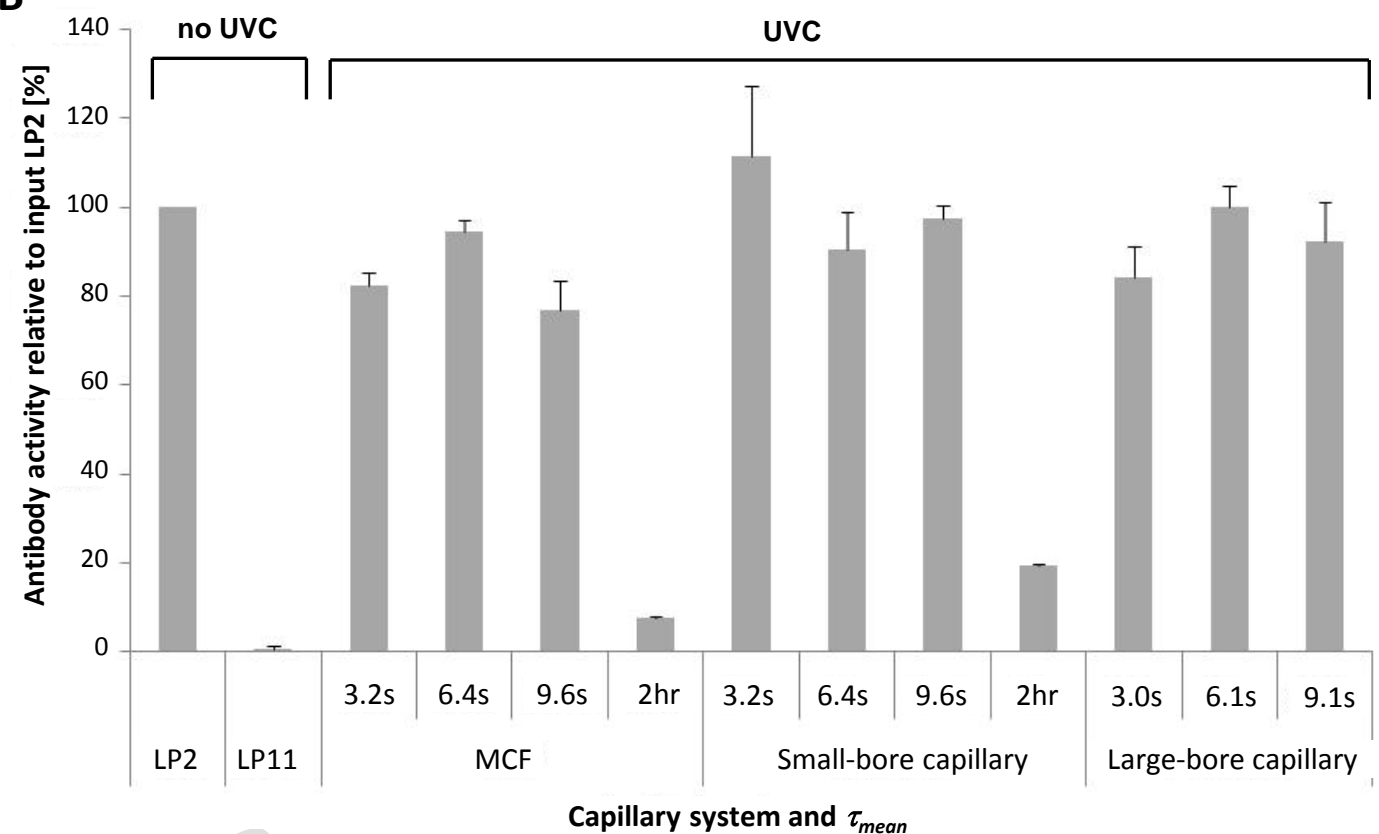

Figure 5 


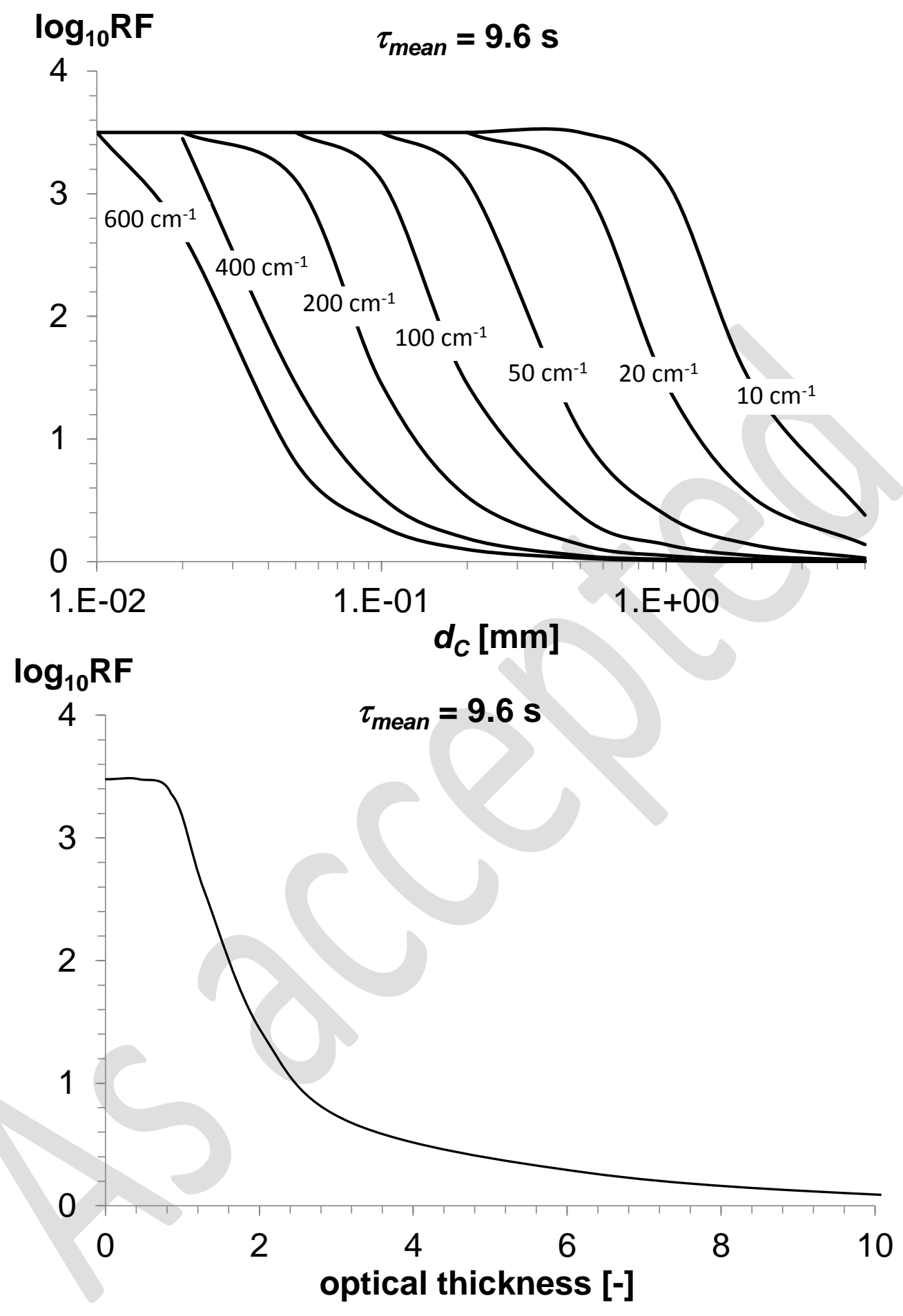

Figure 6 

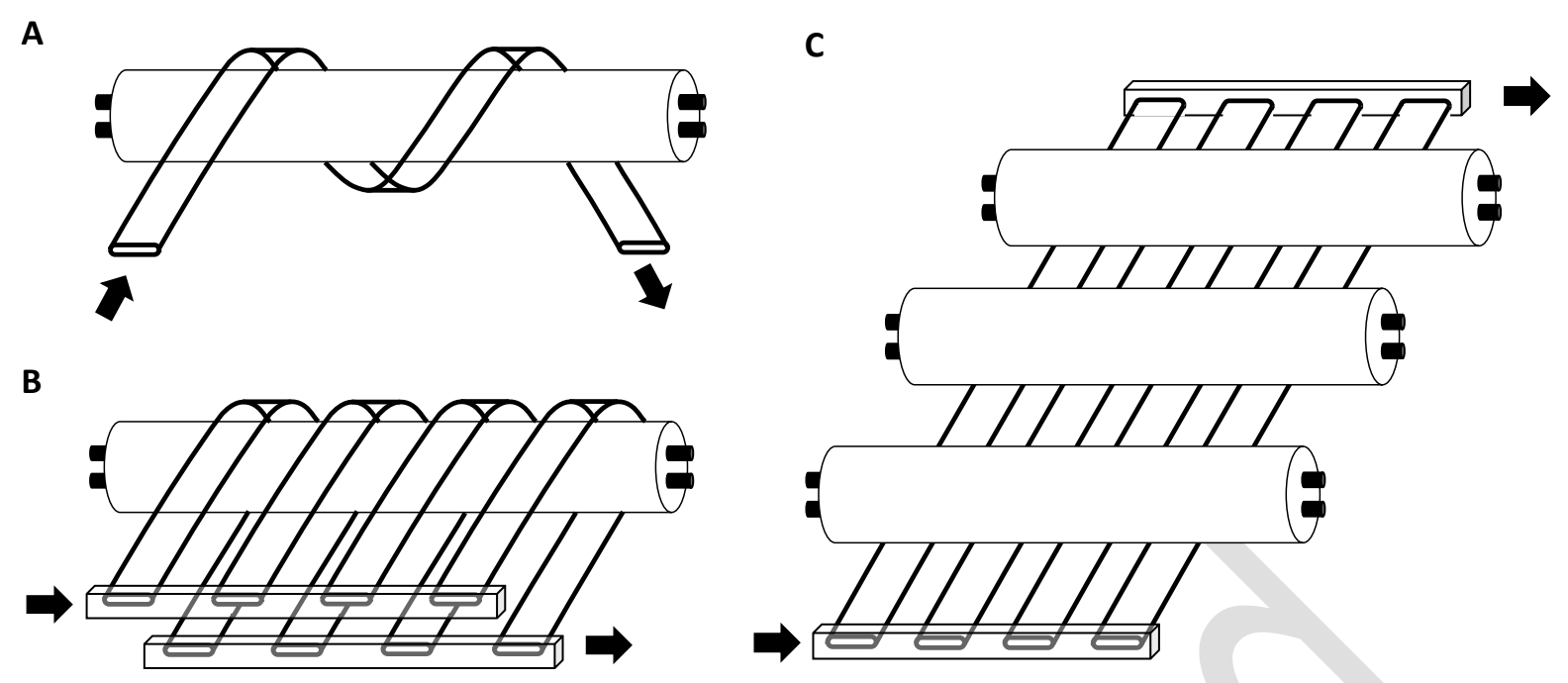

Figure 7 


\section{Graphical Tables of Content}

UVC virus inactivation in optically thick protein solutions is rapid, efficient, non-invasive and scalable based on fluoropolymer microfluidic capillary systems, as demonstrated by a new numerical model and experimental data with a large enveloped HSV-1 virus particles.
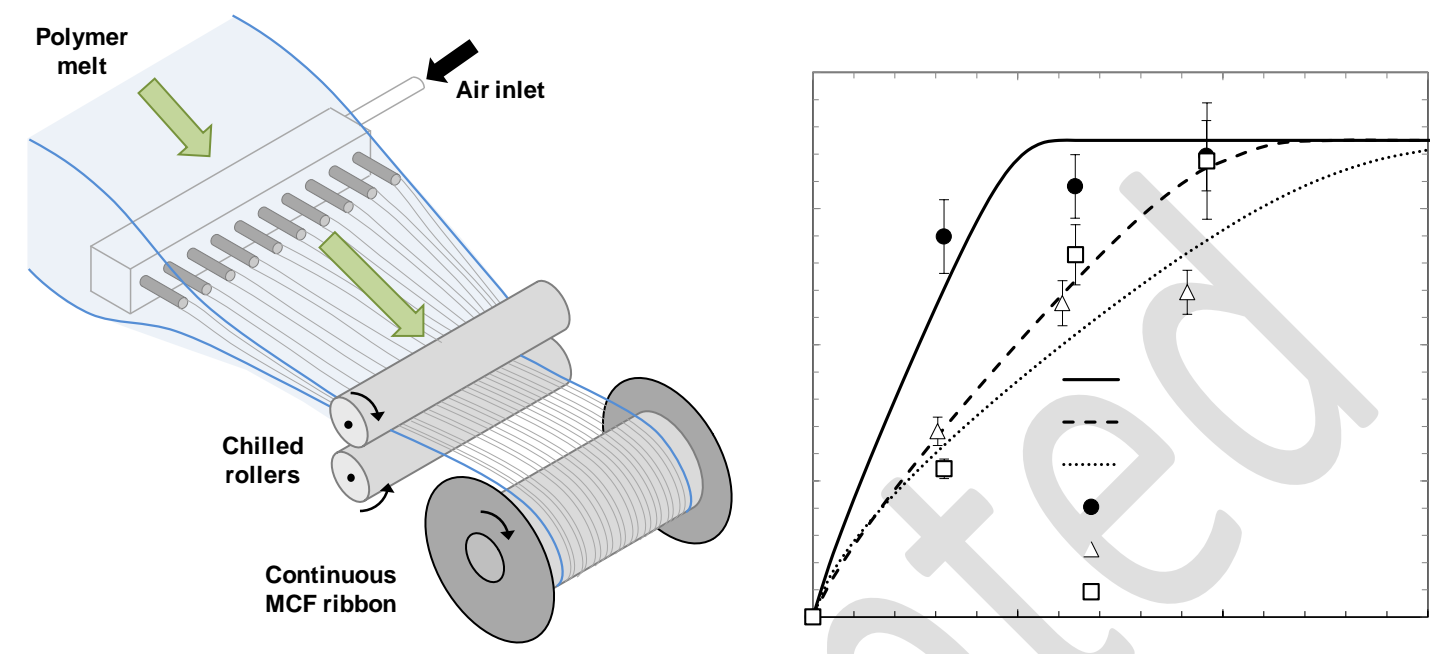